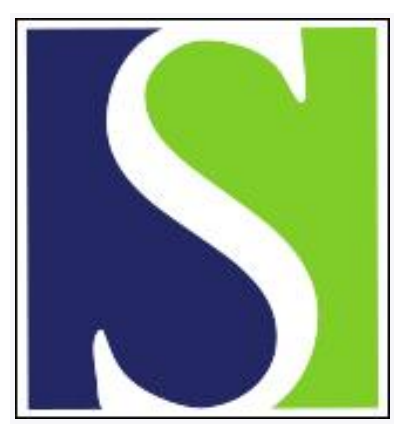

Scand J Work Environ Health 2000;26(2):93-98

https://doi.org/10.5271/sjweh.517

Issue date: Apr 2000

Provocation of electric hypersensitivity under everyday conditions

by Flodin U, Seneby A, Tegenfeldt C

The following article refers to this text: 2004;30(6):486-496

Key terms: double-blind provocation test; skin symptom

This article in PubMed: www.ncbi.nlm.nih.gov/pubmed/10817373

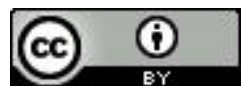




\title{
Provocation of electric hypersensitivity under everyday conditions
}

\author{
by Ulf Flodin, MD, ${ }^{1}$ Agneta Seneby, BSC, ${ }^{1}$ Clas Tegenfeldt, $M S C^{2}$
}

Flodin U, Seneby A, Tegenfeldt C. Provocation of electric hypersensitivity under everyday conditions. Scand $J$ Work Environ Health 2000;26(2):93-98.

\begin{abstract}
Objectives In most previous provocation studies subjects suffering from "electric hypersensitivity" have not been able to determine correctly whether or not they have been subjected to a sham or true provocation to magnetic or electric fields. However, an often-discussed weakness is that most of the earlier provocation studies have been performed in a laboratory situation, often with simulated fields, which may not be representative of conditions prevailing in the homes or workplaces of the patients. Criticism has also been put forth about neglect of the long latency period of symptoms. Therefore, a provocation study was performed in the homes or workplaces of the patients, where we also studied the symptoms and on-off answer 24 hours after the exposure.

Methods Fifteen subjects selected as having fast and distinct reactions from electric equipment were provoked on 4 occasions: mainly 2 true and 2 sham provocations. The intervals between exposure were a few or more days in order to provide the subjects with an opportunity to recover before the next provocation. A control group of healthy subjects with normal hearing and vision verified that the provocations were performed in a blind manner.

Results The patients suffering from "electric hypersensitivity" were no better than the control group in deciding whether or not they were exposed to electric and magnetic fields.

Conclusions Exposure to electric and magnetic fields per se does not seem to be a sufficient cause of the symptoms experienced by this patient group.
\end{abstract}

Key terms double-blind provocation test, skin symptoms.

Since the 1980s skin symptoms from exposure to video screens have been reported in the literature $(1,2)$. Some provocation studies have been performed to clarify the reasons for the symptoms (3-6). In these experiments the subjects suffering from electric hypersensitivity have not been able to determine if they have been subject to fields or a sham provocation.

On the other hand, Rea et al ( 7 ) found some subjects repeatedly experiencing neurological symptoms when exposed to electrical fields in laboratory examinations. Oftedal et al (8) reduced electric fields from visual display unit by using electrically conducting screen filters. Skin symptoms were less severe when the filters were active (earthed) than when they were inactive (unearthed). Stenberg et al (9) found that office workers in buildings with high background electric fields had a higher prevalence of skin symptoms than those in buildings with low fields. Apart from the pure electrical phenomenon, other causes of electric hypersensitivity, such as stress, neuroticism, and psychiatric morbidity, have also been discussed, but no firm associations have so far been found (10).
The objection to previous provocation studies has, among other things, been that most of them have been performed in laboratory situations that may not be representative of the fields prevailing in the homes or workplaces of the patients suffering from "electric hypersensitivity". Therefore the aim of this study was to perform a double-blind provocation test under everyday conditions of patients in order to evaluate if the electric and magnetic fields per se are able to induce the symptoms in this category of patients and if it is possible for them to decide whether or not they are exposed to an increased magnitude of electric and magnetic fields.

\section{Subjects and methods}

\section{Recruitment}

The subjects were recruited from patients who had visited the Department of Occupational and Environmental Medicine at the University Hospital of Linköping in

1 Department of Occupational and Environmental Medicine, Centre for Public Health Sciences, Linköping, Sweden.

2 Bättre Elmiljö, Törnevalla G:a Skola, Linghem, Sweden.

Reprint requests to: Dr Ulf Flodin, Department of Occupational and Environmental Medicine, Centre for Public Health Sciences, S-581 85 Linköping, Sweden. [E-mail ulf.flodin@lio.se] 
1991-1996 or from members of The Swedish Association for the ElectroSensitive living in the county of Östergötland.

The inclusion criteria were (i) symptoms of clear connection with specific electric equipment, (ii) regular reaction occurring within 1 hour of exposure, (iii) no symptoms at home or in the workplace when unexposed to the specific equipment, and (iv) symptoms disappearing within a few days after exposure.

We contacted 44 persons, 13 men and 31 women. Fifteen were included in the study, while 29 were excluded. The most common reason for exclusion was too slow a reaction (14 persons) or refusal to participate because of symptoms that were too strong(10 persons). One person only reacted to fluorescent lamps, which made it impossible to arrange a double-blind provocation. Three persons were treated for different conditions and were excluded. One subject dropped out because of increasingly strong symptoms.

\section{Subjects}

Eleven women and four men [mean 48.3 (range 34-59) years] were included. They had had their symptoms for some years [mean 6.6 (range 2-20) years]. At the debut of their symptoms they had used the specific electric device for between 2 months and 14 years (mean 6.6 years). At the debut of symptoms 13 out of 15 had been using a visual display unit (VDU), while 2 had never used a VDU. However even the 2 without VDU experience reported symptoms from television usage. [Televisions also have a cathode ray tube.] All 15 of the persons in our study were thus exposed to, and experienced symptoms from, exposure to cathode ray tubes. Nine of the subjects worked $75-100 \%$ of full-time. Due to hypersensitivity to electricity 2 were retired, 2 were on $100 \%$ sick leave, and 2 were on $50 \%$ sick leave. There were 3 clerks, 2

Table 1. Electrical devices causing symptoms of electric hypersensitivity in the patients at the time of recruitment.

\begin{tabular}{lc}
\hline Devices & Number \\
\hline Computer & 9 \\
Television & 8 \\
Fluorescent tube & 6 \\
Cellular phone & 5 \\
Sewing machine & 3 \\
Vacuum cleaner & 2 \\
Iron & 2 \\
Electric typewriter & 2 \\
Photocopier & 2 \\
Telephone & 1 \\
Low energy lamp & 1 \\
Stove & 1 \\
Loudspeaker & 1 \\
Lift and decubitus matress & 1 \\
Magnetic field & 1 \\
Transformer & 1 \\
\hline
\end{tabular}

teachers, 2 bookkeepers, 1 youth worker, 1 food industry worker, 1 electrician, 1 nurse, 1 salesman, 1 scientist, 1 bank clerk, and 1 prison warder.

One subject suspected herself of having mercury intoxication from dental fillings, 1 had fibromyalgia, and 1 had rheumatoid arthritis. Four subjects were sensitized to various chemical agents. Six did not take any drugs, and 2 used thyroid drugs. Ten persons had already replaced their amalgam tooth fillings with other dental materials. For treatment for their "hypersensitivity symptoms" 6 had tried acupuncture, and 4 had undergone zone therapy.

At the moment of recruitment the most common electric devices provoking symptoms were VDU ( 9 persons), televisions ( 8 persons), fluorescent lamps ( 6 persons); mobile phones ( 5 persons) (table 1$)$.

The patients recruited the controls. The controls were siblings or friends with good vision and hearing and no hypersensitivity to electricity.

Twenty-six subjects were used as controls. Their mean age was 47 (range 15-77) years, and 16 were female. Because of difficulties in coordinating the test schedules, we had to use more controls than patients.

\section{Methods}

Experimental design. The provocation tests were performed in a double-blind manner in the homes or workplaces of the patients. Our intention was to use electric apparatuses that caused the patients to experience symptoms in their everyday life. But because of difficulties in finding apparatuses for which masking their being on or off would be feasible, we had to use a VDU for most of the provocation tests. Each patient was provoked on 4 occasions for up to 1 hour at a time. In 2 of the provocation tests the apparatus was turned on, and in another 2 it was off. However, for 1 patient there were 3 real exposures and only 1 sham exposure. The statistician in our department randomized the order of true or sham exposures and set the hidden switches inside a black box, accordingly. This information was kept unknown to the research team. The interval between the provocations was $2-32$ days.

The devices used in the provocation of the patients and their controls are shown in table 2 . Thus 4 patients and their controls were provoked merely to their own apparatuses, and another 2 were provoked by their own apparatuses as well as the VDU brought in by the technician (CT). Nine patients and their controls were solely provoked by the VDU supplied by the technician.

Provocation test. At the visit to the home of the patient, the nurse (AS) first performed an interview about the patient's current fitness level using a questionnaire including 13 questions about symptoms. The questions concerned skin, mouth, upper and lower airways, sensations 
from the abdomen and thorax, as well as mental sensations. The patients stated the intensity of each symptom on a scale from 0 to 5 .

Simultaneously the technician (CT) started to mask the apparatuses of the patients. For technical reasons some of the suggested provocation apparatuses of the patients had to be replaced by a VDU brought by the technician. The technician monitored various physical parameters in the test room when the apparatus was off. When the background monitoring was finished, the black box was installed and the current switch was set to on. Then the technician left the room.

After the preparations were finished, the control took a seat in the test room at a distance of 50 centimeters from the apparatus and was asked to judge by means of light, sound, or otherwise whether the apparatus was on or off. The control was given 15 minutes for the task. If he or she could not give a statement, the masking was considered sufficient. Then he or she was asked to guess whether the apparatus was on or off and left the room. If, on the other hand, the control was able to sense if the apparatus was on or off, the mask was improved until the control was not able to judge the status of the apparatus. Neither the technician nor the control had contact with the patient before the provocation of the patient.

Then the patient was introduced. He or she took a seat 50 centimeters in front of the apparatus and was asked every 15 minutes about symptoms listed in the questionnaire. If the patient judged that the apparatus was on, the test was stopped, if not, the test continued for 1 hour.

Then the nurse and patient left the room. The patient got another identical questionnaire to fill out and return 24 hours after the test.

The technician returned to the provocation room and monitored electrical and magnetic fields and unmasked the apparatus. At this moment the technician was not blinded any longer and was not in contact with the patient.

When all the provocation tests were finished, the answers of the subjects were compared with the opened code of the switch board order of on or off. As a safety precaution against the switch board order being mixed up, the results of the monitoring of electric and magnetic fields were compared with the answers of the subjects after each provocation test.

Measurement of background field levels at the exposure site. Background fields were measured at the exposure site for of each of the 15 patients. Artificial illumination and other unnecessary sources of electromagnetic fields were reduced as far as possible. Sources of sound were also minimized. The following parameters were assessed and documented in the form of tables, graphs or both: electric and magnetic fields from static up to $1200 \mathrm{MHz}$ (both far and near fields), lighting level, sound pressure, air pressure, air relative humidity, air temperature, and ionizing radiation. Except for electric and magnetic fields the environmental conditions did not deviate significantly before, after, or between the sites. One important item was the low illumination level due to the avoidance of artificial light sources, the range being $0-680$ lux with a mean level of 92 lux. There were no notable differences between the sites with respect to the signal shape of the electric and magnetic fields in the frequency range of $5-2000 \mathrm{~Hz}$ or $2-400 \mathrm{kHz}$, nor for static fields. There were differences in the radio frequency spectra between the different sites, but each site had more or less constant conditions for each exposure. The results of the background exposure measurements are pertinent also for the sham exposures.

The mean of the power frequency magnetic fields was $47 \mathrm{nT}$ along the $\mathrm{x}$ axis, $63 \mathrm{nT}$ along the $\mathrm{y}$ axis, and 32 $\mathrm{nT}$ along the $\mathrm{z}$ axis, the lowest detected value being $<1$ $\mathrm{nT}$ and the highest being $300 \mathrm{nT}, 300 \mathrm{nT}$ respectively $150 \mathrm{nT}$. The magnitude of the magnetic field strengths in the frequency range of $5-2000 \mathrm{~Hz}$ was $6-150 \mathrm{nT}$ with a mean of $53 \mathrm{nT}$. For the frequency range of $2-$ $400 \mathrm{kHz}$ the magnetic field strengths were below the detection limit of the instrument, which was less than $1 \mathrm{nT}$.

The electric field strength in the $5-2000 \mathrm{~Hz}$ range was between 0.2 and $10 \mathrm{~V} / \mathrm{m}$ with a mean value of 3.0 $\mathrm{V} / \mathrm{m}$. For the frequency range of $2-400 \mathrm{kHz}$, the corresponding value was $0.04-0.4 \mathrm{~V} / \mathrm{m}$ with a mean value of $0.08 \mathrm{~V} / \mathrm{m}$.

Table 2. Devices used as provocation for 15 patients and their individual controls. ${ }^{a}$

\begin{tabular}{lll}
\hline Device & Description & Number of patients \\
\hline 1 & 28-inch color television set & 1 \\
2 & Computer (IBM PC), keyboard, mouse, 14-inch cathode ray tube & 1 \\
3 & 28-inch color television set with integrated plastic contrast filter & 1 \\
4 & 14-inch Copam color monitor (cathode ray tube) & 11 \\
5 & Low-energy lamp (compact fluorescent tube) 11W & 1 (plus device 4) \\
6 & Electric typewriter & 1 (plus device 4) \\
7 & 24-inch color television set & 1 \\
\hline
\end{tabular}

a Six persons used their own apparatus, and two of them used their own apparatus complemented with device 4. Nine persons used only our supplied device 4. 


\section{Exposure measurements}

For each exposure the environmental conditions, as well as the electrical and magnetic fields, were measured before and after the exposure of the controls and the patients. The measurements before the exposure were performed before the black box was switched on, and after the exposure the measurements were made before the black box was switched off.

Table 3. Summary of symptoms of the patients during the provocation tests.

\begin{tabular}{|c|c|}
\hline Symptoms & Number \\
\hline \multicolumn{2}{|l|}{ Throat and mouth } \\
\hline Pricking & 3 \\
\hline Pain & 3 \\
\hline Dryness & 3 \\
\hline Smarting & 2 \\
\hline Mucus secretion & 2 \\
\hline Blisters & 1 \\
\hline Change in taste & 1 \\
\hline \multicolumn{2}{|l|}{ Central nervous effects } \\
\hline Lack of concentration & 4 \\
\hline Headache & 3 \\
\hline Hypersensitivity to light & 3 \\
\hline Hypersensitivity to sound & 2 \\
\hline Dizziness & 2 \\
\hline Sleep disorder & 2 \\
\hline Tiredness & 2 \\
\hline Anxiety & 2 \\
\hline Slurred speech & 1 \\
\hline Memory blanks & 1 \\
\hline Effete & 1 \\
\hline \multicolumn{2}{|l|}{ Skin, foremost face } \\
\hline Redness, burning & 6 \\
\hline Pricking & 6 \\
\hline Swollen or dry eyes & 3 \\
\hline Smarting & 2 \\
\hline Itching & 1 \\
\hline \multicolumn{2}{|l|}{ Various } \\
\hline Abdominal pains & 3 \\
\hline Palpitation & 2 \\
\hline Arthralgia & 2 \\
\hline Generalized ache & 2 \\
\hline Ache in testes & 1 \\
\hline Chest pain & 1 \\
\hline
\end{tabular}

Table 4. Distribution of the correct answers of the patients and controls.

\begin{tabular}{lcccc}
\hline & \multicolumn{2}{c}{ Patients } & & Controls \\
\cline { 2 - 3 } & $\begin{array}{c}\text { During } \\
\text { exposure }\end{array}$ & $\begin{array}{c}24 \text { hours } \\
\text { after } \\
\text { exposure }\end{array}$ & & $\begin{array}{c}\text { During } \\
\text { exposure }\end{array}$ \\
\cline { 2 - 3 } Truly positive & 17 & 19 & 14 \\
Truly negative & 12 & 14 & 16 \\
Sum of correct answers & 29 & 33 & 30 \\
Falsely positive & 17 & 15 & 13 \\
Falsely negative & 14 & 12 & 17 \\
Sum of incorrect answers & 31 & 27 & 30 \\
\hline Total number of answers & 60 & 60 & 60 \\
\hline
\end{tabular}

The magnetic field exposure for the range of 5-2000 $\mathrm{Hz}$ was between 80 and $888 \mathrm{nT}$ with a mean value of $342 \mathrm{nT}$. For the $2-400 \mathrm{kHz}$ range, it was between 11 and $92 \mathrm{nT}$ with a mean of $36 \mathrm{nT}$. The electric field exposure for the range of $5-2000 \mathrm{~Hz}$ was between 130 and $1000 \mathrm{~V} / \mathrm{m}$ with a mean of $288 \mathrm{~V} / \mathrm{m}$. For the range of 2 $400 \mathrm{kHz}$ it was between 1.4 and $40 \mathrm{~V} / \mathrm{m}$ with a mean of $6.2 \mathrm{~V} / \mathrm{m}$. These values constitute a very significant rise in the magnetic and electric fields when compared with the background levels of the sites. Apart from the alternating fields, there were no differences in the environmental conditions before and after each exposure, whether true or sham.

As for the subgroup of 4 patients exposed to their own apparatuses, the mean magnetic exposure was the same as for the rest of the group, the electric field exposure was slightly higher, with a mean of $356 \mathrm{~V} / \mathrm{m}$ and $10 \mathrm{~V} / \mathrm{m}$, respectively, for the $5-2000 \mathrm{~Hz}$ and $2-400$ $\mathrm{kHz}$ ranges. Their sham field exposure with a mean of $36 \mathrm{nT}$ for the $5-2000 \mathrm{~Hz}$ range was slightly lower than the mean of the whole group, while the other parameters did not deviate.

\section{Statistics}

To test the ability of the subjects to discriminate between the on and off situations, the Kruskal Wallis test (11) was used. The Wilcoxon rank sum test was used to test for possible differences in the intensity of the symptoms before and after the true and sham provocations. The Mann Whitney U test was used to compare the ability of the participants to judge whether or not they were subject to a real or sham exposure in relation to the increase in field strength during the real provocations over the background levels.

\section{Results}

The symptoms listed by the patients in the questionnaires after the provocation tests are shown in table 3. It should be noted that each subject could report many symptoms.

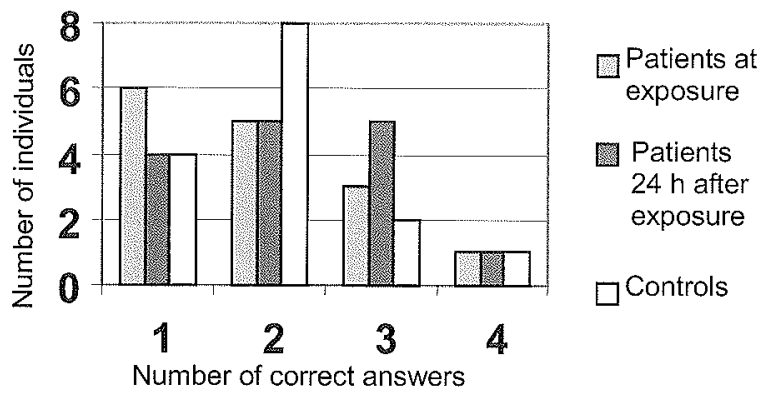

Figure 1. Distribution of the correct answers of the patients and controls. 
Fifteen patients were provoked on 4 occasions (ie, a total of 60 provocation tests. For each person, current was on during 2 tests and off during 2 . During the tests the patients gave 17 truly positive and 12 truly negative answers, as well as 17 falsely positive and 14 falsely negative answers (table 4), for a total of 31 incorrect and 29 correct answers. The results of the patients were close to those of the controls, the difference not being statistically significant (chi-square $=0.09, \mathrm{P}=0.7$ ). Twenty-four hours after their tests the patients made a second judgment of the on or off status of the apparatus of provocation. These results, too, did not differ between the patients and controls (table 4 ) (chi-square $=0.44, \mathrm{P}=0.51$ ).

It was only possible to test 4 patients using their own apparatus. The results of this subgroup did not differ from those provoked with the standard apparatus. The 4 subjects gave 6 correct and 10 incorrect answers during the tests. Twenty-four hours after the tests 9 answers were true and 7 were false (not shown in table).

The distribution of the number of correct answers of the patients and controls is given in the histogram in figure 1 . One patient and one control gave 4 correct answers. On the whole, there was no statistically significant difference between the patients and controls (chi-square = $0.07, \mathrm{P}=0.97$ ).

To evaluate any difference in the intensity of some 10 symptoms on the 6-grade scale given in the questionnaires before and after the real and sham provocation, the Wilcoxon rang sum test was used. No differences in the intensity of the respective symptoms were observed $(\mathrm{P}=0.5)$.

We also analyzed the number of correct answers of the patients in relation to the relative and absolute increase in electric or magnetic fields during the provocation when compared with the background values. No correlation between increased fields and the number of correct answers was observed using the Mann Whitney $U$ test $(\mathrm{P}$-value at lowest $=0.19)$.

\section{Discussion}

Hypersensitivity to electricity is a controversial condition, but of interest since many people consider themselves affected, especially in Sweden. There are however also reports of this condition from other countries, for example, Norway, Denmark, and Japan (6). Some people are on sick leave due to symptoms ascribed to hypersensitivity to electricity, although this condition is not accepted as a diagnosis. The persons who believe they suffer from this condition are very difficult to treat. They are often convinced of their diagnosis. When discussing the existence of this condition, these patients claim that earlier provocation studies were not performed in situations representative of the patients. Therefore we decid- ed to design a study in which we took the objections of the patients to earlier provocation studies into account.

The objective was to use the subjects' own devices for the exposure, but the majority of them did not have a suitable device. By suitable we mean devices which, in fact, do emit electric and magnetic fields and for which it is possible to mask the sound, light and other emissions apart from fields. We also demanded that the device give symptoms within an hour of exposure. The shielding was made of black plastic sheets, glass wool, cardboard and textile. There were no distortions of electric and magnetic alternating fields due to the mask. The static electric field strength was affected by the use of insulating materials, which in some cases resulted in a surface charge. Most of the surface charges present at the exposure sites were due to synthetic fabrics (clothes, carpets, etc), the static buildup on the shielding was created by the handling of the insulating materials. The surface charges of the shields diffused rapidly and were well below $\pm 100 \mathrm{~V}$ after a few minutes. The static surface charge of the cathode ray tube (VDU or television) was masked by the shielding. Physical parameters also affected by the masking were heat (convection as well as infrared radiation), light (including ultraviolet), chemical emissions, and sound, all of which were masked as intended. The temperature inside the (shielded) device rose above the specifications $\left(>70^{\circ} \mathrm{C}\right)$ during the true exposures due to the heat generated in the enclosure.

As for the sometimes discussed cofactor for electric hypersensitivity, mental stress, the provocations were performed in a quiet and undemanding situation. However, some people may have felt the provocation situation itself was somewhat stressful since the task was to make a decision as to whether the provocation was real or sham.

It is important to note that the difference in the fields from a real device and a simulated one, as well as between different devices, can be vast. Thus it was our intention to use only devices giving symptoms for each person. It is also important to know that the fields can differ if the device is active or passive while the power is on. For example, a computer monitor has an electric field that varies with the image content. The same is true for television sets, but then the user has no influence on the variation. To increase the electric field strength, we ran all the devices, even those constructed for earthed power outlets, without a protective earth connection.

The patients were not able to make a more precise judgment than the controls or chance as to whether they had been subject to a real or sham exposure. This result is in agreement with that of some other reports $(3-6)$, but it contradicts others (7-9).

Some earlier examinations have been performed in laboratory situations $(3-7)$, while others have taken place in workplaces $(8,9)$. Only one study found an 
association between magnetic fields and symptoms (7), while two found a connection between alternating electric fields and symptoms $(8,9)$. Two of the three positive studies were performed in the workplaces of the patients $(8,9)$, while one was carried out in a laboratory (7). To our knowledge our study is the first to be carried out mainly in the homes of patients, where we also observed conceivable slow reactions up to 24 hours after the provocation. Our primary intention was to use the apparatuses of the patients during the provocation, but for practical reasons it was possible only for 4 persons. Their results did, however, not differ from those of the rest of our patients. In common for the 3 positive studies (7-9) was the registration of the subjects' symptoms (ie, alteration in number of symptoms or the intensity of symptoms). In the negative provocation studies, an onoff judgment of the subjects (3-6) was used. We assumed that it could be difficult for subjects to interpret their subjective feelings from the skin and other symptoms as a basis for deciding whether or not they were really exposed. We therefore analyzed both the on-off judgment and the possible changes in the intensity of symptoms before and after sham and real provocation. However, no difference in subjective symptoms correlating with the type of exposure was observed.

Recently reported results showed that 10 electrical hypersensitivity patients exposed to flickering light had a higher amplitude for visual evoked potential of the occipital brain cortex than did controls (12). Since flickering light from fluorescent tubes is often present in VDU workplaces, the observation is of great interest. In our study however, we avoided artificial light in order not to interfere with the exposure. In a follow-up study we will test the hypothesis that a particular type of light must be present before electromagnetic fields provoke symptoms.

In conclusion, we were not able to find that electric hypersensitivity patients are more able than controls to judge if they are exposed to electrical and magnetic fields or not, nor was there any correlation between changes in symptom intensity and the real versus sham exposure situations.

\section{References}

1. Lindén $\mathrm{V}$, Rolfsen S. Video computer terminals and occupational dermatitis [letter to the editor]. Scand I Work Environ Health $1981 ; 7: 62-7$.

2. Nilsen A. Facial rash in visual display unit operators. Contact Dermatitis 1982;8:25-8.

3. Swanbeck G, Bleeker T. Skin problems from visual display units. Acta Derm Venereol (Stockh) 1989;69:46-51.

4. Hamnerius Y, Agrup G, Galt S, Nilsson R, Sandblom J, Lindgren $R$. Provocation study of hypersensitivity reactions associated with exposure to electromagnetic fields from VDUs [abstract]. In: Luczakh, Cakir AE, Cakir G, editors. Third International Scientific Conference on Work with Display Units, 1992. September 1-4. Berlin: Technische Universität Berlin, 1992:A-17-A-18.

5. Wennberg A, Franzén O, Paulsson L-E. Detektion av elektriska och magnetiska fält [Detection of electric and magnetic fields]. Solna (Sweden): Arbetsmiljöinstitutet, 1990. Undersökningsrapport 20,

6. Andersson B, Berg M, Arnetz B, Melin L, Langlet I, Lidén S. A cognitive behavioural treatment of patients suffering from "electric hypersensitivity". J Occup Environ Med 1996; 38:752-8.

7. Rea WJ, Pan Y, Fenyves E J, Sujisawa I, Samadi N, Ross GH Electromagnetic field sensitivity. J Bioelectricity 1991; $10: 241-56$.

8. Oftedal G, Vistnes A I, Rygge K. Skin symptoms after the reduction of electric fields from visual display units. Scand J Work Environ Health 1995;21:335-44.

9. Stenberg B, Eriksson M, Hansson Mild K, Höög J, Sandström M, Sundell J, et al. Facial skin symptoms in VDT workers: a case-referent study of personal, psychosocial building and VDT related risk indicators. Int J Epidemiol 1995;24:796803.

10. Berg M, Arnetz B. An occupational study of employees with VDU-associated symptoms: the importance of stress. Stress Med 1996;12:51-4.

11. Altman D. Practical Statistics for medical research. London: Chapman and Hall, 1997.

12. Sandström M, Lyskov E, Berglund A, Medvede S, Hansson Mild K. Neurophysiological effects of flickering light in patients with perceived electrical hypersensitivity. J Occup Environ Med 1997;39:15-22.

Received for publication: 18 May 1999 